\title{
Research on the Factors Affecting Regional Smog in China-Based on Spatial Panel Model
}

\author{
Honglei Chen, Boyun Xue \\ Department of Economy, Jinan University, Guangzhou, China \\ Email: xueboyun941009@163.com
}

How to cite this paper: Chen H.L. and Xue, B.Y. (2019) Research on the Factors Affecting Regional Smog in China-Based on Spatial Panel Model. Modern Economy, 10, 1292-1309.

https://doi.org/10.4236/me.2019.104088

Received: March 21, 2019

Accepted: April 20, 2019

Published: April 23, 2019

Copyright ( 2019 by author(s) and Scientific Research Publishing Inc. This work is licensed under the Creative Commons Attribution International License (CC BY 4.0).

http://creativecommons.org/licenses/by/4.0/

(c) (i) Open Access

\begin{abstract}
Based on the PM2.5 concentration values of 30 provinces in China from 1998 to 2016, this study empirically analyzes the influencing factors of smog pollution by using spatial Durbin model. The study found that smog pollution in China has significant spatial spillover effects and spatial characteristics of high-high (low-low) aggregation. And through the method of spatial Durbin model, it is found that the smog pollution in China is time-dependent due to the significant influence of its lag term. In terms of driving factors, it is found that there is a significant inverted U-shaped curve relationship between smog pollution and economic growth. In terms of driving factors, it is found that there is a significant inverted $U$-shaped curve relationship between smog pollution and economic growth. The industrial structure with high proportion of the second industry, urbanization measured by urban population, and coal-based energy structure significantly aggravate the smog pollution in our country. In view of the spatial spillover effect and time lag effect of smog pollution in China, it is necessary to strengthen regional joint prevention and control. And it is also supposed to optimize industrial structure, achieve clean and efficient use of resources, rationalize urbanization, and encourage public transportation and new energy vehicles.
\end{abstract}

\section{Keywords}

Smog Pollution, Spatial Spillover Effect, Driving Factors, Spatial Durbin Model

\section{Introduction}

Since the reform and opening up, China's economic development has grown rapidly, and the process of urbanization and industrialization has continued to advance. However, along with the improvement of people's living standards, environmental pollution has gradually become a problem that plagues society, es- 
pecially in recent years, which has seriously threatened people's daily life and health. In 2013, China and especially the eastern region suffered from severe and long-lasting smog pollution. Therefore, smog began to attract people's attention, and even became the annual keyword in 2013. The 2017 China Ecological Environment Bulletin shows that in 2017, only 99 of the 338 cities in China achieved environmental air quality standards, and the remaining 239 cities had excessive ambient air quality. At present, smog pollution spreads widely and it is difficult to control. Therefore, smog pollution becomes one of the most difficult problems in environmental protection. Due to smog, the visibility of the road is low, which not only affects people's normal travel, but also increases the risk of traffic accidents. In addition, sulfur dioxide, nitrogen oxides and respirable particulate matter are the main components of smog. These three pollutants especially PM 2.5 cause great harm to the human body, so smog will pose a great threat to public health.

In order to cope with the increasingly serious pollution situation, the government has repeatedly introduced various governance measures and included environmental governance into the " $13^{\text {th }}$ Five-Year Plan". In 2013, the State Council also issued the "Air Pollution Prevention and Control Action Plan". In 2017, the government further put forward the slogan of "Resolutely Fighting the Blue-Sky Defense War" in the two sessions and issued the "Three-Year Action Plan to Win the Blue-Sky Defense War" in 2018.

Many social and economic factors will cause smog pollution, so it is necessary to examine the impact of these factors, which can better identify the leading factors and provide a basis for scientific management of smog. Therefore, we will use the concentration values of PM 2.5 as the explanatory variable. And we will use the spatial measurement model for empirical analysis to reasonably identify the factors affecting smog. This paper is organized as follows: the second part is a literature review; the third part is method, including model theory and data; the fourth part is empirical research, including spatial autocorrelation, regression analysis and results; the fifth part is conclusions and policy recommendations.

\section{Literature Review}

In recent years, scholars have increasingly explored the factors affecting smog from the perspective of social science. Most studies have considered factors that will affect air pollution, such as economic development level, industrial structure, urbanization, energy structure, and transportation and foreign direct investment (FDI). In terms of economic development level, most scholars study whether there is an inverted U-shaped curve between smog pollution and economic growth based on the environmental Kuznets curve theory. Some scholars believe that this hypothesis is true, but others hold opposing views. Among them, based on the provincial PM 2.5 panel data from 1998 to 2012, Shao Shuai et al. [1] found that the economic development would aggravate smog pollution firstly and then began to reduce, which was a U-shaped curve. However, other 
scholars hold opposing views, such as Ma Limei and Zhang Xiao [2]. Relying on the spatial environment Kuznets curve regression model, they found that when using smog pollution as an environmental variable the relationship between smog pollution and economic growth was not satisfied Kuznets hypothesis. The smog pollution was positively correlated with economic growth. Qi Shaozhou and Yan Yaxue [3] conducted research by using the panel threshold model. And they believed that in most cities the environmental Kuznets curves presented a positive " $U$ " shape, while in other cities the curves presented a weak positive " $U$ " shape or a monotonically increasing linear relationship. However, only in few cities, the curves had inverted " $U$ " type. Liu Huajun and Yan Yanfeng [4] used the spatial Tobit model for empirical regression. The results also supported the view that the environmental Kuznets hypothesis was not true. But he believed that there was a linear diminishing relationship between smog and the economy. In terms of industrial structure, scholars measure industrial structure from different angles and use different indicators to characterize smog pollution. However, no matter what kind of measurement is used, most scholars agree that industrial structure will aggravate pollution. Among them, Leng Yanli and Du Sizheng [5] added the intersection of industrial structure and urbanization in the model, and studied the 30 provinces in China into inland areas and coastal areas respectively. The results showed that the increasement of proportion of industrial added value would aggravate smog pollution, and the impact in coastal areas was worse. Liu Xiaohong and Jiang Keshen [6] constructed the panel FMOLS regression and found that the proportion of the secondary industry increased significantly worsen the PM 2.5 concentration. He Feng and Ma Dongdong [7] used the cross-section Tobit model to study the relationship between smoggy days and industrialization. The results showed that industrialization would increase smoggy days. In terms of urbanization, literature studies use different methods to measure urbanization, but the conclusion is similar that urbanization has a negative impact on smog pollution. Liu Chenyue and Xu Yingzhi [8] used the mediating effect method to test the effect of population urbanization, land urbanization and industrial urbanization on smog pollution. Population urbanization and industrial urbanization could directly aggravate smog pollution and also affect smog pollution indirectly through other means. But land urbanization could not significantly affect smog pollution. Liu Bolong et al. [9] introduced the lag term of smog pollution by means of the improved STIRPAT model. Finally, they found that urbanization would increase the pollution level. Qin Meng et al. [10] used the PM 2.5 concentration, global nighttime lighting and LandScan data to calculate the urban sprawl index, and studied the impact of urban sprawl on urban air pollution. It was found that urban population increase and spatial expansion would aggravate pollution, but the impact depended on the size of the city. In terms of energy, most articles take the proportion of coal resources as an explanatory variable, and believe that the proportion of coal has a positive effect on smog pollution. Ma Limei and Zhang Xiao [11] considered the influence of spa- 
tial effects based on the theory of environmental economics. The analysis found that the energy structure had a significant correlation with smog pollution, and the sub-regional study found that the north smog pollution was more serious than the south. Ma Limei et al. [12] believe that China's current coal-based energy structure was the most direct factor affecting smog pollution in the central and western regions, especially in the central region. Li Zhenyu et al. [13] discussed the consumption structure of coal, oil and gas, and believed that pollutants from coal and fuel emissions contributed to smog weather. Lei Ming [14] creatively established an energy-resource-economy-environment integrated input-output table to analyze and predict the China's energy and economic environment from 1992 to 2020, and found that the use of coal, especially in the process of power generation, would affect China's future air quality. In terms of transportation, Ma Limei et al. [12] believed that traffic was the most direct factor affecting smog in the later stages of industrialization. The impact of traffic factors on smog pollution was more severe in the east. In terms of foreign direct investment, the current research is mainly based on the hypothesis of "pollution heaven" for foreign direct investment and environmental pollution. Leng Yanli et al. [15] believed that foreign direct investment would aggravate smog pollution, that is, "pollution heaven" existed. And two sub-samples of coastal and inland studies found that the impact of foreign direct investment in different regions was different. Yan Yaxue and Qi Shaozhou [16] used the spatial panel model to empirically analyze, and found that foreign direct investment was an important reason to smog. Li Li et al. [17] used PM 10 to measure the smog pollution in the Pearl River Delta region. He found that the "pollution heaven" hypothesis did not hold in the Pearl River Delta region. Yan Yaxue and Qi Shaozhou [18] also considered the spatial factors and found that FDI in most parts of China had obvious adverse effects on the environment. However, Zhou Li and $\mathrm{Li}$ Jing [19] analyzed the PM 2.5 data published by the NASA, and found that the "pollution heaven" hypothesis was established nationwide.

In conclusion, the economic research on smog pollution mainly adopts the input-output method, the computable general equilibrium (CGE) method and the typical empirical analysis method. Only a few studies use spatial models to analysis. However, as a kind of air pollution, smog pollution is not a simple local environmental problem, so ignoring spatial effects will lead to inaccurate empirical analysis results. And because China's smog data began to publish recently, few research use these data. So, this paper takes the annual average concentration values of PM 2.5 as the research object, and takes into account the spatial effect to accurately identify the influencing factors and provide a reasonable decision basis.

\section{Method}

\subsection{Spatial Autocorrelation}

Based on the understanding of the geographical relevance of all things, driven by 
the continuous development of geographic information systems, spatial econometrics has gradually entered people's field of vision, and through the continuous expansion of the definition of spatial econometrics, spatial econometrics has become one of the most important econometric methods.

There might be spatial autocorrelations in smog pollution among adjacent cities. If it does have spatial autocorrelations, then we need to apply the spatial econometric techniques to analyze. So, we should examine the spatial autocorrelation at first. Spatial autocorrelation can be divided into global spatial autocorrelation and local spatial autocorrelation from the perspective of the whole and part of the region.

The test of global spatial autocorrelation can be judged by the global Moran index and the Geary index.

Global Moran Index:

$$
I=\frac{\sum_{i=1}^{n} \sum_{j=1}^{n} w_{i j}\left(Y_{i}-\bar{Y}\right)\left(Y_{j}-\bar{Y}\right)}{S^{2} \sum_{i=1}^{n} \sum_{j=1}^{n} w_{i j}}
$$

where $S^{2}=\frac{\sum_{i=1}^{n}\left(Y_{i}-\bar{Y}\right)^{2}}{n}$ represents the sample variance, $\bar{Y}=\frac{\sum_{i=1}^{n} Y_{i}}{n}, Y_{i}$ represents the observed value of region $i, \mathrm{n}$ represents the total number of regions, and $w_{i t}$ represents the spatial weight matrix element.

The Moran index $I$ value is between -1 and 1 . And greater than 0 means positive spatial autocorrelation, that is, there are spatial features of high-high aggregation and low-low aggregation; less than 0 means negative spatial autocorrelation, that is, there are spatial features of high-low aggregation; equal to or close to 0 means no spatial autocorrelation, that is, spatial distribution is random.

Another commonly used indicator is the Geary index:

$$
C=\frac{(n-1) \sum_{i=1}^{n} \sum_{j=1}^{n} w_{i j}\left(Y_{i}-\bar{Y}\right)^{2}}{2\left(\sum_{i=1}^{n} \sum_{j=1}^{n} w_{i j}\right)\left(\sum_{i=1}^{n}\left(Y_{i}-\bar{Y}\right)^{2}\right)}
$$

The value of the Geary index $\mathrm{C}$ is between 0 and 2. Unlike the Moran index, the larger the value of the Geary index, the more negative the autocorrelation. Therefore, when the Gary index is greater than 1, it is negatively correlated. When less than 1, it means positive correlation, and equal to 1 means irrelevant.

Local spatial autocorrelation test can be judged by the local Moran index. The local Moran index reflects the condition of spatial autocorrelation near a region.

Local Moran Index:

$$
I=\frac{Y_{i}-\bar{Y}}{S^{2}} \sum_{j=1}^{n} w_{i j}\left(Y_{j}-\bar{Y}\right)
$$

The meaning of the local moran index is similar to that of the global moran index, and is still when the index is positive, showing a state of high-high or low-low aggregation; the index is negative, showing high-low Aggregation status. 


\subsection{Spatial Econometric Models}

The spatial econometric models for spatial autocorrelation could be considered as the extensions of conventional regression models by incorporating the spatial effects explicitly.

The general form of the spatial model is:

$$
\begin{gathered}
Y=\rho W Y+X \beta+W X \delta+\mu \\
\mu=\varphi W \mu+\varepsilon, \quad \varepsilon \sim N\left(0, \sigma^{2} I_{n}\right)
\end{gathered}
$$

where $W$ is the $N \times N$-order spatial weight matrix. $W Y$ is the spatial lag variable of the inter variable, which means the effect of dependent variable of adjacent region; $W X$ is the spatial lag variables of the explanatory variables, which means the effect of explanatory variables of adjacent region; $W \mu$ implies the interaction of random error terms. According to the values of $\rho, \delta$ and $\varphi$, it can be transformed into spatial Durbin model; spatial lag model, also known as spatial autoregression and spatial error model.

The spatial lag model (SLM) can be written as:

$$
Y=\rho W Y+X \beta+\varepsilon, \quad \varepsilon \sim N\left(0, \sigma^{2} I_{n}\right)
$$

The spatial error model (SEM) can be written as:

$$
\begin{gathered}
Y=X \beta+\mu \\
\mu=\lambda W \mu+\varepsilon, \quad \varepsilon \sim N\left(0, \sigma^{2} I_{n}\right)
\end{gathered}
$$

The spatial Durbin model (SDM) can be written as:

$$
Y=\rho W Y+X \beta+W X \delta+\alpha l_{n}+\varepsilon, \quad \varepsilon \sim N\left(0, \sigma^{2} I_{n}\right)
$$

The spatial Durbin model considers the spatial lag of the explanatory variable $W X$, which is when studying the explanatory variables of a certain region, the explanatory variables of other regions will also affect the research objects of the region. Adding the spatial lag of the explanatory variables can effectively prevent the omitted errors, so this paper will use the spatial Durbin model for analyzing.

\section{Empirical Research}

\subsection{Spatial Autocorrelation Analysis of China's}

\subsubsection{Global Spatial Autocorrelation}

Table 1 shows the Moran index value and the Geary index value of the PM 2.5 concentration of the 30 provinces from 1998 to 2016 under the weight of the 0 1 adjacency matrix. It can be seen that under the weight matrix $\mathrm{W} \_1$, the global Moran index is significantly larger than 0 , and the index values are between 0.4 and 0.55 . The Geary index is also significantly less than 1 , with the index value between 0.3 and 0.4 . It shows that China's smog pollution has positive spatial autocorrelation, that is, provinces with higher PM 2.5 concentration are adjacent to other provinces with higher concentration, and provinces with lower PM 2.5 concentration are adjacent to other low-concentration provinces, so the spatial distribution of smog pollution is high-high aggregation and low-low aggregation. 
Table 1. Global Moran's I and Geary's C index values for PM2.5 1998-2016 (0 - 1 adjacency matrix weight $\mathrm{W}$ ).

\begin{tabular}{|c|c|c|c|c|c|c|}
\hline index & & Moran's & I & & Geary's & $\mathrm{C}$ \\
\hline year & I & $\mathrm{z}$ & p-value ${ }^{*}$ & $\mathrm{C}$ & $\mathrm{z}$ & p-value \\
\hline 1998 & 0.428 & 4.224 & 0.0000 & 0.366 & -3.797 & 0.0000 \\
\hline 1999 & 0.468 & 4.51 & 0.0000 & 0.397 & -4.081 & 0.0000 \\
\hline 2000 & 0.478 & 4.623 & 0.0000 & 0.379 & -4.02 & 0.0000 \\
\hline 2001 & 0.466 & 4.594 & 0.0000 & 0.317 & -3.99 & 0.0000 \\
\hline 2002 & 0.503 & 4.835 & 0.0000 & 0.31 & -4.609 & 0.0000 \\
\hline 2003 & 0.532 & 5.087 & 0.0000 & 0.28 & -4.864 & 0.0000 \\
\hline 2004 & 0.536 & 5.11 & 0.0000 & 0.301 & -4.784 & 0.0000 \\
\hline 2005 & 0.533 & 5.083 & 0.0000 & 0.341 & -4.537 & 0.0000 \\
\hline 2006 & 0.491 & 4.761 & 0.0000 & 0.32 & -4.267 & 0.0000 \\
\hline 2007 & 0.549 & 5.218 & 0.0000 & 0.316 & -4.769 & 0.0000 \\
\hline 2008 & 0.528 & 5.054 & 0.0000 & 0.309 & -4.634 & 0.0000 \\
\hline 2009 & 0.489 & 4.727 & 0.0000 & 0.319 & -4.417 & 0.0000 \\
\hline 2010 & 0.519 & 4.964 & 0.0000 & 0.336 & -4.496 & 0.0000 \\
\hline 2011 & 0.523 & 5.016 & 0.0000 & 0.306 & -4.59 & 0.0000 \\
\hline 2012 & 0.53 & 5.054 & 0.0000 & 0.318 & -4.72 & 0.0000 \\
\hline 2013 & 0.51 & 4.936 & 0.0000 & 0.316 & -4.304 & 0.0000 \\
\hline 2014 & 0.531 & 5.089 & 0.0000 & 0.331 & -4.453 & 0.0000 \\
\hline 2015 & 0.516 & 4.923 & 0.0000 & 0.318 & -4.766 & 0.0000 \\
\hline 2016 & 0.53 & 5.1 & 0.0000 & 0.307 & -4.441 & 0.0000 \\
\hline
\end{tabular}

Figure 1 and Figure 2 show the Moran scatter plot of China's smog pollution in 2010 and 2016. The first and third quadrants of the Moran scatter plot indicate that there is a positive spatial autocorrelation, which indicates the spatial distribution characteristics of high-high or low-low aggregation of PM 2.5 concentration in China. The second and third quadrants indicate that there is a negative spatial correlation, which indicates a state in which a province having a low PM 2.5 concentration is surrounded by a province having a high concentration and a state in which a province having a high concentration is surrounded by a province having a low concentration. It can be seen from the figure that the number of provinces located in the first and third quadrants is significantly larger than that of the second and fourth quadrants, thus further verifying the positive spatial autocorrelation of smog pollution in China.

\subsubsection{Local Spatial Autocorrelation}

Global spatial autocorrelation reflects the overall spatial dependence and may ignore individual characteristics. Therefore, local spatial correlation analysis of smog pollution is needed. The analysis can use the local moran index to analyze.

It can be seen that the provinces shown in Table 2 are high-high aggregation 


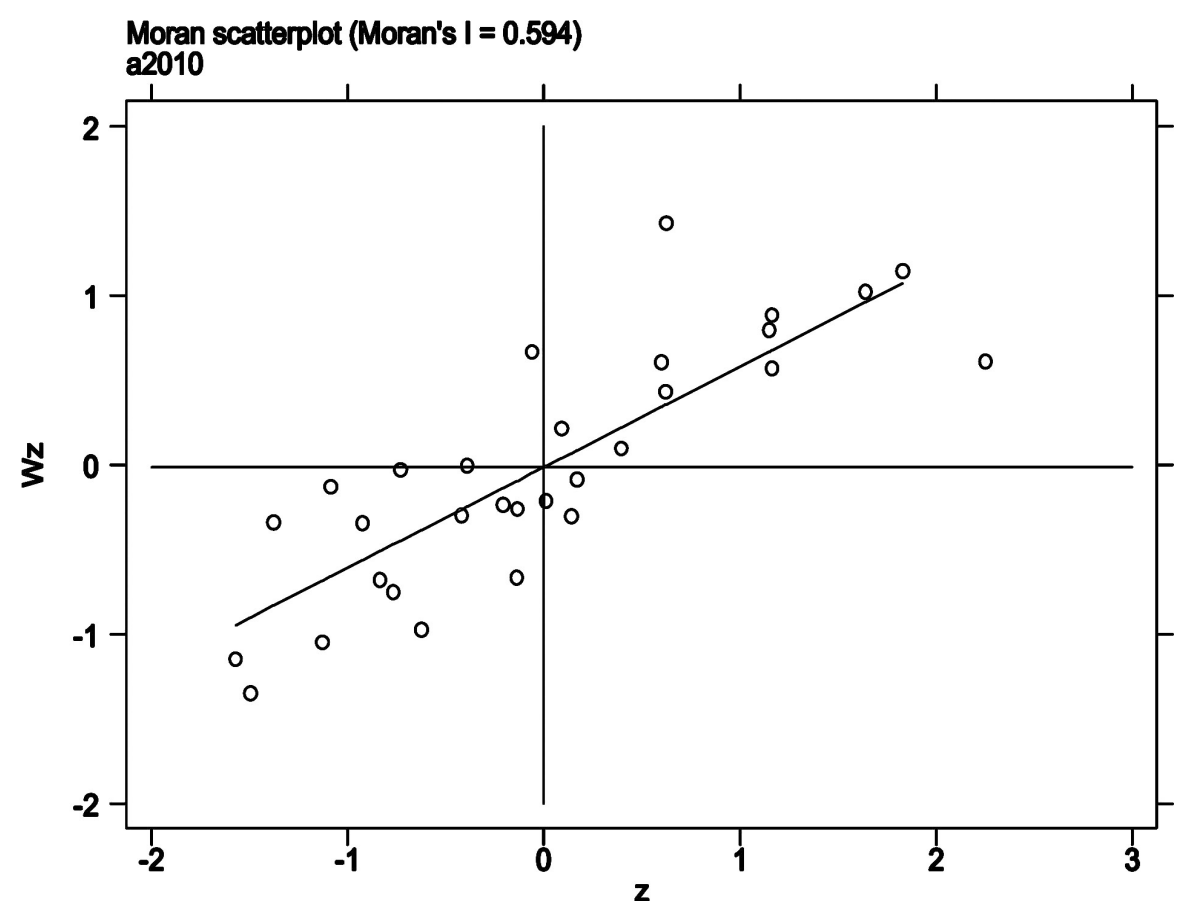

Figure 1. Moran scatter plot of smog pollution in 30 provinces of China in 2010.

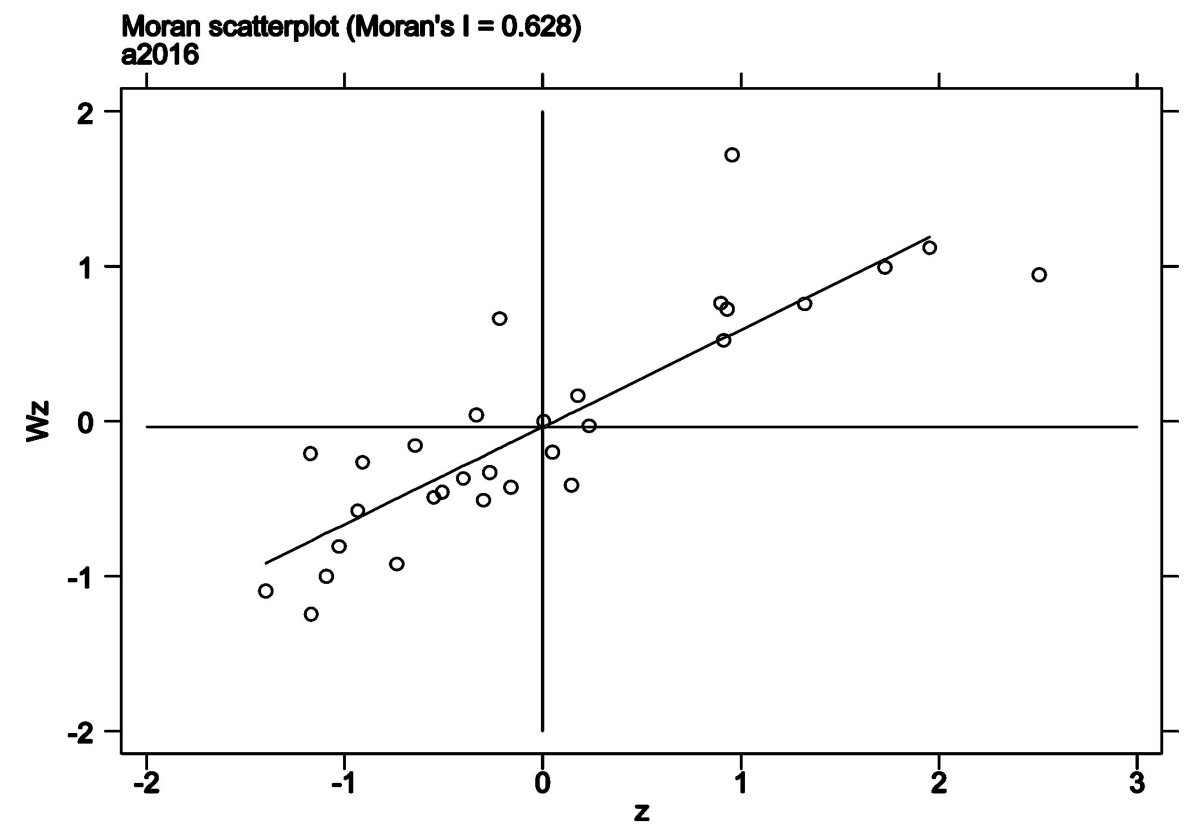

Figure 2. Moran scatter plot of smog pollution in 30 provinces of China in 2016.

Table 2. Provinces with high-high aggregation in 2010, 2012, 2014 and 2016.

\begin{tabular}{cc}
\hline Year & Provinces \\
\hline 2010 & Beijing, Tianjin, Hebei, Shandong, Henan, Anhui, Jiangsu, Shanghai, Hubei \\
2012 & Beijing, Tianjin, Hebei, Shandong, Henan, Anhui, Jiangsu, Shanghai \\
2014 & Beijing, Tianjin, Hebei, Shandong, Henan, Anhui, Jiangsu, Shanghai \\
2016 & Beijing, Tianjin, Hebei, Shandong, Henan, Anhui, Jiangsu, Shanghai \\
\hline
\end{tabular}


of smog pollution in 2010, 2012, 2014 and 2016, all of which belong to North China and Central China.

\subsection{Regression Model and Variables}

\subsubsection{Regression Model}

In order to further analyze the effects of economic growth, industrial structure, urbanization and energy structure on PM 2.5 pollution, we incorporate the variables of economic growth, industrial structure, urbanization and energy structure into the spatial Durbin model and thus expand the model as follows:

$$
\begin{aligned}
& \ln p m_{i t}=\rho_{i t} \ln p m_{i t}+\beta_{0}+\beta_{1} \ln p e r g d p_{i t}+\beta_{2}\left(\ln \operatorname{pergdp} p_{i t}\right)^{2} \\
& +\beta_{3} \ln \text { industry }_{i t}+\beta_{4} \ln \text { urban }_{i t}+\beta_{5} \ln e s_{i t}+\beta_{6} X_{i t} \\
& +\delta_{1} w_{i t} \ln \text { pergdp } p_{i t}+\delta_{2} w_{i t}\left(\ln \text { pergdp } p_{i t}\right)^{2}+\delta_{3} w_{i t} \ln \text { industry }_{i t} \\
& +\delta_{4} w_{i t} \ln u_{r b a n}+\delta_{5} w_{i t} \ln e s_{i t}+\varepsilon_{i t} \\
& \varepsilon_{i t} \sim N\left(0, \sigma_{i t}^{2}\right)
\end{aligned}
$$

\subsubsection{Variables}

The statistical description of each variable is shown in Table 3.

Interpreted variables: 1998-2016 annual average concentration of PM 2.5 of 30 provinces in China.

Explanatory variables: 1) Regional per capita GDP (pergdp). In order to measure the level of economic development in each region, this paper uses regional per capita GDP and introduces a secondary item of per capita GDP. 2) Industrial structure (industry). In addition to industry, Shao Shuai [1] believes that along with the rapid development of China's construction industry, construction dust has also become a major factor affecting smog. Therefore, this paper uses the ratio of the secondary industry to GDP, including industry and construction, to reflect the industrial structure. 3) Urbanization level (urban). This paper uses the proportion of regional urban population to the total population to measure the level of urbanization. 4) Energy structure (es). In this paper, we measure the consumption

Table 3. The statistical description of each variable.

\begin{tabular}{cccccc}
\hline Variable & Obs & Mean & Std. Dev. & Min & Max \\
\hline pm & 570 & 29.50789 & 16.04358 & 2.25 & 82.67 \\
pergdp & 570 & 26936.67 & 22702.94 & 2364 & 118198 \\
industry & 570 & 45.72247 & 7.920292 & 19.26 & 61.5 \\
urban & 570 & 0.484191 & 0.156217 & 0.2189 & 0.896 \\
es & 570 & 0.957302 & 0.359908 & 0 & 2.306218 \\
transport & 570 & 19.77987 & 31.82539 & 0.705882 & 205.4727 \\
human & 570 & 8.28337 & 1.102035 & 4.906216 & 12.38909 \\
rfdi & 570 & 7.781601 & 7.989141 & 0 & 70.42974 \\
popdens & 570 & 2161.566 & 1620.776 & 25 & 22609 \\
\hline
\end{tabular}


of coal resources in energy consumption as an indicator of energy structure.

Control variables: 1) Traffic factor (transport). This paper refers to the method of Ma Limei et al. [12], using the ratio of private car ownership to road mileage to measure the traffic pressure in the region. 2) Actual foreign capital utilization amount (rfdi). According to the current US dollar to RMB exchange rate, the actual amount of foreign investment is converted into RMB units, and then divided by the actual GDP of the year. 3) Human capital (human). This paper draws on the method of Chen et al. [20] to measure the human capital by multiplying the population with different education levels in the region by the average years of education of different educational levels and the ratio of the total population in the region. Where $P_{i t}$ represents the total population, $E_{i t}=E_{1, i t} \times 6+E_{2, i t} \times 9+E_{3, i t} \times 12+E_{4, i t} \times 16$ indicates education level, $E_{1, i t}, E_{2, i t}, E_{3, i t}$ and $E_{4, i t}$ represent the population of primary, middle, high school, college and above, respectively, so the human capital is $E_{i t} / P_{i t}$. 4) Population density (popdens). This paper measures the population density by the number of people per unit area in each region.

\subsection{Results}

\subsubsection{Static Spatial Durbin Model Results}

The results in Table 4 show that the spatial autocorrelation coefficient is 0.992 , which is significant at the $1 \%$ level, indicating that the smog pollution in the adjacent area has a positive impact on the smog pollution in the region. That is the degree of smog pollution in the adjacent area increases, the smog pollution in this area will intensify. The conclusion that the smog pollution has a spatial spillover effect is consistent with the previous moran index test.

The detailed results are:

1) Economic growth. From the regression results of the model in Table 4, it can be seen that the first term (lnpergdp) coefficient of per capita GDP is 0.488 , which is significantly positive, while the quadratic term (sqlnpergdp) is -0.023 , which is significantly negative. It can be said that there is a significant inverted " $U$ " relationship between China's economic growth and smog pollution, that is, China's smog pollution will increase with the growth of the economy at first and then it will be reduced, thus verifying China's environmental Kuznets curve (EKC) hypothesis.

2) Industrial structure. It can be seen from Table 4 that the industrial structure shows a positive impact on the smog pollution at a significant level of $10 \%$. That is, the proportion of the secondary industry increases, and the smog pollution will be significantly increased. And through the spatial lag variable of the industrial structure (WInindustry ${ }_{i t}$ ), it can be seen that the increase in the proportion of the secondary industry in the adjacent region has a significant effect on this region.

3) Urbanization. The results show that the regression coefficient of urbanization indicators is significantly positive, indicating that the advancement of urbanization in China will aggravate the pollution of smog. The reason may be the increase in the level of urbanization and population concentration leads to a sig- 
nificant increase in consumer demand for production and life. All of this will make pollutant emissions increase. In addition, the urban spatial lag variable $\left(\right.$ Wlnurban $_{i t}$ ) has a negative coefficient, indicating that the urbanization process of the neighboring province will alleviate the smog pollution in the province. The possible explanation is that the urbanization process in the surrounding provinces has led to a loss of population in observed province. Then it will reduce the pollutant emissions of observed province.

4) Energy structure. The regression results in Table 4 show that the increase in coal consumption will significantly increase the level of smog pollution. China's coal energy consumption has become an important reason for the frequent smog weather in China. However, some scholars have suggested that coal is not the "culprit" of smog, but the extensive use of coal has caused smog pollution. Therefore, in view of the future coal will still be the main energy source in China, the management of smog pollution should pay attention to the clean and efficient use of coal while striving to develop clean energy.

Table 4. Spatial Durbin model regression results.

\begin{tabular}{|c|c|c|c|}
\hline \multicolumn{3}{|c|}{$\operatorname{lnpm}$} & \multirow{2}{*}{$\begin{array}{c}\operatorname{lnpm} \\
0.992^{* * *}\end{array}$} \\
\hline & & $\mathrm{W}{ }^{\star} \mathrm{lnpm}$ & \\
\hline & & & $(0.092)$ \\
\hline \multirow[t]{2}{*}{ lnpergdp } & $0.488^{\star * *}$ & $\mathrm{~W}^{*}$ lnpergdp & 0.394 \\
\hline & $(0.186)$ & & $(0.296)$ \\
\hline \multirow[t]{2}{*}{ sqlnpergdp } & $-0.023^{\star *}$ & $\mathrm{~W}^{*}$ sqlnpergdp & -0.016 \\
\hline & $(0.009)$ & & $(0.014)$ \\
\hline \multirow[t]{2}{*}{ lnindustry } & $0.102^{*}$ & $\mathrm{~W}^{\star}$ lnindustry & $0.368^{* * *}$ \\
\hline & $(0.052)$ & & $(0.090)$ \\
\hline \multirow[t]{2}{*}{ lnurban } & $0.274^{\star * *}$ & $\mathrm{~W}^{\star} \ln u r b a n$ & -0.028 \\
\hline & $(0.068)$ & & $(0.124)$ \\
\hline \multirow[t]{2}{*}{ es } & $0.126^{* * *}$ & $\mathrm{~W}^{*}$ es & 0.075 \\
\hline & $(0.027)$ & & $(0.058)$ \\
\hline \multirow[t]{2}{*}{ rfdi } & 0.001 & & \\
\hline & $(0.001)$ & & \\
\hline \multirow[t]{2}{*}{ lnhuman } & -0.048 & & \\
\hline & $(0.113)$ & & \\
\hline \multirow[t]{2}{*}{ lnpopdens } & $-0.027^{* * *}$ & & \\
\hline & $(0.007)$ & & \\
\hline \multirow[t]{2}{*}{ lntransport } & -0.008 & & \\
\hline & $(0.014)$ & & \\
\hline \multirow[t]{2}{*}{$\rho$} & $0.765^{\star * *}$ & & \\
\hline & $(0.027)$ & & \\
\hline $\mathrm{R}^{2}$ & 0.686 & & \\
\hline
\end{tabular}

Standard errors in parentheses. ${ }^{*} \mathrm{p}<0.10,{ }^{* *} \mathrm{p}<0.05,{ }^{* * *} \mathrm{p}<0.01$. 


\subsubsection{Spatial Effect Decomposition}

When there are spatial spillover effects, it can be decomposed into direct effects and indirect effects. The direct effect indicates the magnitude of the influence of the explanatory variables in the region on the interpreted variables in the region. The indirect effect indicates the extent to which the region affects adjacent areas. The three effects of smog pollution in China are decomposed below.

From the spatial effect decomposition results in Table 5, it can be seen that the three effects of economic growth are positive, and the total effect and the direct effect are both significant at the level of $1 \%$. This shows that economic growth not only improves local but also increases pollution levels in adjacent areas. The spatial regression coefficients of indirect effects and the total effects of the industrial structure are 0.157 and 0.264 , respectively. These two effects are significantly positive at the $1 \%$ level, and the direct effect regression coefficient is positive, 0.107 , at the $5 \%$ level, which indicates the increase of the proportion of the second industry will not only aggravate the smog pollution in the province, but also intensify pollution in neighboring provinces. The direct and total effects of the urbanization level are significantly positive, but the regression coefficient of the indirect effect is -0.023 , indicating that the improvement of urbanization level will significantly increase the level of smog pollution in the local region. But the urbanization of adjacent areas will reduce smog pollution of local region. The direct effect of the energy structure is significantly positive. Although the total effect and the indirect effect are not significant, the coefficients are both positive, indicating that the increase in local coal consumption will increase the smog pollution in the region and adjacent areas.

\subsubsection{Dynamic Spatial Durbin Model Results}

Since the static spatial Durbin model often ignores the influence of factors other than explanatory variables and control variables on smog pollution, this paper

Table 5. Static spatial effect decomposition of spatial Durbin model.

\begin{tabular}{cccc}
\hline Variables & Total effect & Direct effect & Indirect effect \\
\hline lnpergdp & $0.861^{* * *}$ & $0.495^{* * *}$ & 0.366 \\
& $(0.288)$ & $(0.192)$ & $(0.289)$ \\
sqlnpergdp & $-0.038^{* * *}$ & $-0.023^{* *}$ & -0.015 \\
& $(0.014)$ & $(0.009)$ & $(0.014)$ \\
lnindustry & $0.264^{* * *}$ & $0.107^{* *}$ & $0.157^{* * *}$ \\
& $(0.094)$ & $(0.051)$ & $(0.092)$ \\
lnurban & $0.253^{* *}$ & $0.276^{* * *}$ & -0.023 \\
& $(0.129)$ & $(0.064)$ & $(0.119)$ \\
es & 0.196 & $0.125^{* * *}$ & 0.071 \\
& $(0.057)$ & $(0.026)$ & $(0.060)$ \\
$R^{2}$ & 0.686 & & \\
\hline
\end{tabular}

Standard errors in parentheses. ${ }^{\star} \mathrm{p}<0.10,{ }^{* *} \mathrm{p}<0.05,{ }^{* * *} \mathrm{p}<0.01$ 
uses the lag term of the PM2.5 concentration value as an explanatory variable to establish dynamic spatial panel model.

It can be seen from Table 6 that the fitness of the dynamic spatial Durbin model $R^{2}=0.844$ is higher than that of the static spatial Durbin model $R^{2}=0.686$, indicating that the dynamic Durbin model is more accurate than the static Durbin model. The table shows that the spatial autocorrelation coefficient of the dynamic spatial Durbin model is 0.961 at $1 \%$ significant level. The spatial autocorrelation relationship is positive, which is same as that in static spatial Durbin model. It means that smog pollution in the adjacent area will affect smog pollution in local area. In the dynamic Durbin model, the coefficient of the first-order lag of PM 2.5 is positive at the $1 \%$ significance level, indicating Table 6. Dynamic spatial Durbin model regression results.

\begin{tabular}{|c|c|c|c|}
\hline \multicolumn{3}{|c|}{$\operatorname{lnpm}$} & \multirow{2}{*}{$\frac{\operatorname{lnpm}}{0.961^{* * *}}$} \\
\hline & & $\mathrm{W}^{\star} \operatorname{lnpm}$ & \\
\hline & & & $(0.102)$ \\
\hline \multirow[t]{2}{*}{ Lag.lnpm } & $0.354^{* * *}$ & $\mathrm{~W}^{\star}$ Lag.lnpm & $0.323^{* * *}$ \\
\hline & $(0.041)$ & & $(0.062)$ \\
\hline \multirow[t]{2}{*}{ lnpergdp } & $0.370^{* *}$ & $\mathrm{~W}^{\star}$ lnpergdp & 0.429 \\
\hline & $(0.189)$ & & $(0.341)$ \\
\hline \multirow[t]{2}{*}{ sqlnpergdp } & $-0.016^{*}$ & $\mathrm{~W}^{*}$ sqlnpergdp & -0.023 \\
\hline & $(0.009)$ & & $(0.016)$ \\
\hline \multirow[t]{2}{*}{ lnindustry } & 0.021 & $\mathrm{~W}^{\star}$ lnindustry & 0.177 \\
\hline & $(0.057)$ & & $(0.125)$ \\
\hline \multirow[t]{2}{*}{ lnurban } & $0.182^{* *}$ & $\mathrm{~W} *$ lnurban & -0.107 \\
\hline & $(0.073)$ & & $(0.134)$ \\
\hline \multirow[t]{2}{*}{ es } & $0.074^{* * *}$ & $\mathrm{~W}^{\star}$ es & 0.060 \\
\hline & $(0.026)$ & & $(0.060)$ \\
\hline \multirow[t]{2}{*}{ rfdi } & 0.000 & & \\
\hline & $(0.001)$ & & \\
\hline \multirow[t]{2}{*}{ lnhuman } & $-0.388^{\star \star \star}$ & & \\
\hline & $(0.146)$ & & \\
\hline \multirow[t]{2}{*}{ lnpopdens } & $-0.015^{\star *}$ & & \\
\hline & $(0.008)$ & & \\
\hline \multirow[t]{2}{*}{ lntransport } & -0.014 & & \\
\hline & $(0.017)$ & & \\
\hline \multirow[t]{2}{*}{$\rho$} & 0.025 & & \\
\hline & $(0.089)$ & & \\
\hline$R^{2}$ & 0.844 & & \\
\hline
\end{tabular}

Standard errors in parentheses. ${ }^{*} \mathrm{p}<0.10,{ }^{* *} \mathrm{p}<0.05,{ }^{* * *} \mathrm{p}<0.01$. 
that the smog pollution in China is has time lag effect. Therefore, on the one hand, the increase of smog pollution in past period will significantly increase the smog pollution in this period. On the other hand, other unconsidered factors will have a significant impact on smog pollution. Therefore, it is shown that the dynamic spatial Durbin panel model is more accurate than static. The directions of coefficient of the explanatory variable and spatial lag variable in the dynamic model are the same as that in the static model. It also shows that there is an inverted " $U$ " relationship between economic growth and smog pollution. Industrial structure, urbanization and energy structure all aggravate smog pollution.

From the regression results in Table 7, it can be seen that the direct and total effects of economic growth on smog pollution are significantly positive both in the short-term and long-term, and the indirect effects of the two phases are positive, indicating the increase in demand due to economic growth has made the pollution problem more serious. In terms of industrial structure, the short-term effects are all positive that the increase in the proportion of the secondary industry in the short term will aggravate the smog pollution. In the long run, the total effect and indirect effect of the industrial structure are negative, probably because of in the long-term the adjustment of the local regional industrial structure is beneficial to the adjacent areas, thus reducing the smog pollution in local region through feedback. In terms of urbanization, the level of short-term urbanization has increased, and the level of smog pollution has also increased. However, in the long run, the total effect and the direct effect are positive, and the indirect effect is negative, indicating that the advancement of urbanization makes the technical level and the educated population in local region are continuously improving, which is benefit to solve the smog pollution problem. But for the surrounding areas, local urbanization may lead to the loss of talents in the surrounding areas, so that the level of technological innovation and the level of

Table 7. Dynamic spatial effect decomposition.

\begin{tabular}{ccccccc}
\hline \multirow{2}{*}{ variables } & \multicolumn{3}{c}{ Short-term effect } & \multicolumn{3}{c}{ Long-term effect } \\
\cline { 2 - 7 } & Total effect & Direct effect & Indirect effect & Total effect & Direct effect & Indirect effect \\
\hline Inpergdp & $0.777^{* *}$ & $0.385^{* *}$ & 0.392 & $0.801^{* *}$ & $0.564^{*}$ & 0.237 \\
& $(0.334)$ & $(0.182)$ & $(0.344)$ & $(0.344)$ & $(0.328)$ & $(0.468)$ \\
sqlnpergdp & $-0.038^{* *}$ & $-0.017^{*}$ & -0.021 & $-0.039^{* *}$ & -0.024 & -0.015 \\
& $(0.016)$ & $(0.009)$ & $(0.017)$ & $(0.017)$ & $(0.016)$ & $(0.023)$ \\
lnindustry & 0.202 & 0.021 & 0.181 & -0.165 & 0.069 & $-0.233^{*}$ \\
& $(0.133)$ & $(0.054)$ & $(0.116)$ & $(0.137)$ & $(0.090)$ & $(0.142)$ \\
lnurban & $0.278^{* *}$ & $0.185^{* *}$ & 0.093 & $-0.287^{* *}$ & $-0.288^{* *}$ & 0.001 \\
& $(0.139)$ & $(0.074)$ & $(0.131)$ & $(0.143)$ & $(0.129)$ & $(0.173)$ \\
es & 0.141 & $0.075^{* * *}$ & 0.066 & -0.010 & $-0.137^{* * *}$ & $0.127^{*}$ \\
& $(0.057)$ & $(0.025)$ & $(0.056)$ & $(0.059)$ & $(0.045)$ & $(0.072)$ \\
\hline
\end{tabular}

Standard errors in parentheses. ${ }^{*} \mathrm{p}<0.10,{ }^{* *} \mathrm{p}<0.05,{ }^{* *} \mathrm{p}<0.01$. 
$\mathrm{R} \& \mathrm{D}$ investment will be reduced, which is not conducive to the solution of environmental problems. In terms of energy structure, the increase in coal energy consumption in the short term is harmful to air quality. In the long run, it is no longer extensive use of coal but clean and efficient use. Then the smog pollution will be reduced.

On the whole, comparing the dynamic spatial Durbin model of smog pollution with the results of the static spatial Durbin model, the estimated coefficients of the variables are consistent and the significance is basically the same, indicating that the effect of different factors is credible.

\section{Conclusions}

Along with the development of China's economy, the environmental problems are getting worse. Therefore, the effective identification of the key factors affecting smog pollution is necessary. Based on the existing literature, this paper verifies the spatial spillover effect of smog pollution, and uses the spatial panel models to empirically analyze the key driving factors of smog pollution. The results show that the inter-provincial smog pollution has positive global spatial autocorrelation and positive local spatial autocorrelation, which means that China's smog pollution has a significant spatial spillover effect. And through the comparison of static and dynamic spatial Durbin models, China's smog pollution is not only spatially dependent, but also affected by past smog pollution, that is, there is a path dependence in time. The concrete conclusion is that with the development of China's economy, the phenomenon of smog pollution in China will deteriorate first and then gradually repair. China's high proportion of the second industry, coal resource consumption and urbanization have made the smog pollution increasingly serious. China's smog pollution presents path dependence and spatial spillover effects in the time dimension and spatial dimension respectively. Therefore, the measures to control smog should focus on the continuity of policy and joint prevention and control between regions.

In light of the above conclusions, the main recommendations are as follows.

1) Realize regional joint prevention and control. If the management of smog relies only on unilateral treatment, it is difficult to solve the pollution problem in China. Solving the problem of air pollution requires coordination and cooperation among various regions, and actively builds a coordinated governance system in which multiple social entities participate. The government should clarify the responsibilities of the various regional entities and prevent the "free-riding" behavior of local governments. The government should also establish a unified environmental pollution monitoring platform to achieve environmental information sharing within the region. The government is also expected to establish incentive, compensation and punishment mechanisms within the region, and increase the assessment of public satisfaction.

2) Implement regional differentiated governance measures. Due to the different levels of smog pollution in various regions of China, the spatial distribution 
characteristics are different and the level of economic development is also different. Therefore, it should be based on local characteristics and uneven economic development levels. In economic developed region, the improvement of innovation level of high-tech industries is encouraged. Other regions with relatively backward economies can manage the smog by optimizing traditional industries.

3) Promote green, advanced and rationalized industrial structure. The government should use technological innovation to upgrade traditional industries, which can speed up the elimination of backward production capacity and resolve the contradiction of overcapacity. Besides, the government also should improve the environmental protection requirements of industries and the access standards for high-energy and high-pollution industries. Thus it can limit the rapid growth of pollution intensive industry. It is also possible to force the green upgrading of the industrial structure through market-oriented environmental regulation tools, such as the regulation of emissions trading futures in the emissions trading market, and the imposition of pollution taxes.

4) Change the extensive use and develop new energy sources. The government can encourage independent research and development by reward individuals or enterprises, which allows new technology to improve energy efficiency and reduce the proportion of coal in the energy structure. As China's coal resources are abundant, coal will continue to be the main energy source in the future, so the government should establish a scientific, efficient, clean and sustainable coal consumption system to prevent energy waste. The government should also develop new and renewable energy sources such as solar energy, wind energy and nuclear energy. Also the government should strengthen the development and utilization of other energy sources such as natural gas, coalbed methane and shale gas.

5) Reasonably promote the process of urbanization. The urbanization should be people-oriented and ecological. So the government should increase the urban green area and create a green urbanization. Also the government should plan urban public transportation systems, increase public transportation, and encourage public access to public transportation. In addition, the government should increase the propaganda of new energy vehicles and increase subsidies for the purchase of new energy vehicles.

\section{Conflicts of Interest}

The authors declare no conflicts of interest regarding the publication of this paper.

\section{References}

[1] Shao, S., Li, X., Cao, J.H. and Yang, L.L. (2016) Economic Policy Choice of China's Haze Pollution Control-Based on the Perspective of Spatial Spillover Effect. Economic Research, 51, 73-88.

[2] Ma, L.M. and Zhang, X. (2014) The Spatial Effect of Smog Pollution in China and the Impact of Economic and Energy Structure. China Industrial Economy, 24, 
19-31.

[3] Qi, S.Z. and Yan, Y.X. (2017) Research on Kuznets Curve of Chinese Haze (PM2.5) Based on Panel Threshold Model. Journal of Wuhan University (Philosophy and Social Sciences), 70, 80-90.

[4] Liu, H.J. and Pei, Y.F. (2017) Environmental Kuznets Curve Test of Smog Pollution in China. Statistical Research, 34, 45-54.

[5] Leng, Y.L. and Du, S.Z. (2015) Industrial Structure, Urbanization and Haze Pollution. China Science and Technology Forum, 9, 49-55.

[6] Liu, X.H. and Jiang, K.S. (2016) Research on the Relationship between Urbanization, Industrial Structure and Smog Dynamics in China-An Empirical Test Based on Provincial Panel Data. Ecology and Economy, 32, 19-25.

[7] He, F. and Ma, D.D. (2015) Relationship between Smog and Industrialization Development-An Empirical Study of 74 Cities in China. Soft Science, 29, 110-114.

[8] Liu, C.Y. and Xu, Y.Z. (2017) How Does Urbanization Affect the Pollution Control of Smog?-An Empirical Study Based on Mediating Effect. Economic Management, 8, 6-23.

[9] Liu, B.L., Yuan, X.L. and Zhang Z.J. (2015) The Impact of Urbanization on Smog Pollution-An Empirical Analysis Based on China's Provincial Dynamic Panel Data. Urban Development Research, 22, 23-27+80.

[10] Qin, M., Liu, X.Y. and Tong, Y.T. (2016) Does the Sprawling Urban Space Aggravate the Smog Pollution? Empirical Analysis from China PM2.5 Data. Finance and Trade Economics, 11, 146-160.

[11] Ma, L.M. and Zhang, X. (2014) Spatial Effects of Regional Air Pollution and Industrial Structure Impact. China Population, Resources and Environment, 24, 157-164.

[12] Ma, L.M., Liu, S.L. and Zhang, X. (2016) Energy Structure, Traffic Model and Haze Pollution-Based on Spatial Econometric Model. Finance and Trade Economics, 1, 147-160.

[13] Li, Z.Y., Huang, G.X., Li, D.J. and Ren, J. (2013) Analysis of the Causes and Prevention Measures of Foggy Weather in Beijing from the Perspective of Energy Consumption Structure. Contemporary Petroleum and Petrochemical, 21, 11-16.

[14] Lei, M. (1998) Research on Resource-Economy-Environment Input-Output Accounting Application-China Energy-Resource-Economy-Environmental Comprehensive Analysis (1992-2020). Quantum Economics and Technology Economics Research, 11, 59-63.

[15] Leng, Y.L., Xian, G.M. and Du, S.Z. (2015) Foreign Direct Investment and Haze Pollution-An Empirical Analysis Based on Chinese Provincial Panel Data. International Trade Issues, 12, 74-84.

[16] Yan, Y.X. and Qi, S.Z. (2017) Foreign Direct Investment and China's Haze Pollution. Statistical Research, 5, 69-81.

[17] Li, L., Tang, D.L., Kong, Y., Liu, D.J. and Yang, Y.H. (2016) A Spatial Econometric Study of the Impact of FDI on Urban Haze Pollution-Taking the Pearl River Delta Region as an Example. Management Review, 28, 11-24.

[18] Yan, Y.X. and Qi, S.Z. (2017).Time and Space Effect of Foreign Direct Investment on Pollution of Urban Haze (PM2.5) in China. China Population, Resources and Environment, 27, 68-77.

[19] Zhou, L. and Li, J. (2015) Foreign Direct Investment and PM2.5 Air Pollution-Re-Testing of the "Contamination Shelter" Hypothesis Based on Chinese Da- 
ta. International Economics and Trade Research, 31, 98-111.

[20] Chen, Z., Lu, M. and Jin, Y. (2004) Regional Differences in Human Capital and Education Development in China: Estimation of Panel Data. World Economy, 12, $25-31+77$ 